\title{
Pengembangan Pantai Dreamland Sebagai Daerah Tujuan Wisata
}

Elya Kennis Rozana a, 1, I Nyoman Sunarta a, 2

1elya.rozana@yahoo.com, ${ }^{2}$ nyoman_sunarta@unud.ac.id

a Program Studi S1 Destinasi Pariwisata, Fakultas Pariwisata,Universitas Udayana, Jl. Dr. R. Goris, Denpasar, Bali 80232 Indonesia

\begin{abstract}
In a development of tourist destination area has several stages that can show the position and situation of development in that tourist destination area. Dreamland Beach is located in the south of Bali precisely in the Pecatu area.

This research aims to provide an overview of the existing conditions of Dreamland Beach in terms of tourism product components and the development of Dremland Beach, also explore suitable strategies for Dreamland Beach development. This research used qualitative descriptive data analysis and analysis using SWOT. Theories and concepts that used are the concept of beach, touris destination area, development and theory of Butler or tourism area life cycle.

The result of this study is indicate the existing condition of Dreamland Beach that viewed from the components of tourist attraction products. The Facilities and infrastructure is support but still lacking. The acces road to Dreamland Beach is nice and easy to reach and additional service are still overlapping and not yet comprehensive. The development of Dreamland Beach is still in the stage involvement. As well as a suitable develompmet of Dreamland Beach is to maintain the cleanliness of the beach and open new access to attract tourists, providing easy access to the location of Dreamland Beach to overcome the competition with other tourist destination, open new access and do promotion more vigorously to attract more tourists to visit Dreamland Beach.
\end{abstract}

Keywords : existing conditions, components of tourism products, the development of tourist destination areas, the development of tourist destinations

\section{PENDAHULUAN}

Sektor pariwisata belakangan ini begitu diminati dan banyak pula daerah-daerah yang gencar mengembangkan sektor pariwisata. Sehingga terdapat banyak daerah tujuan wisata baru bermunculan. Setiap daerah tujuan wisata memiliki keunikan tersendiri yang dapat membuat daerah tujuan wisata tersebut berbeda dengan yang lain. Belakangan ini daerah tujuan wisata yang begitu diminati yaitu kawasan pantai. Semakin banyak kawasan pantai yang sekarang telah dikembangkan menjadi daerah tujuan wisata, sehingga persaingan antar daerah tujuan wisata pun tidak dapat dihindari.

Dalam perkembangannya daerah tujuan wisata memiliki beberapa tahapan atau fase yang dapat menunjukkan pada posisi dan situasi perkembangan daerah tujuan wisata tersebut. Teori tersebut disebut dengan siklus hidup area destinasi (tourist area life cycle). Teori siklus hidup area destinasi (tourist area life cycle) tersebut menunjukkan bahwa kondisi daerah tujuan wisata tidak selalu tetap melainkan mengalami perubahan dari waktu ke waktu, baik perubahan mengalami peningkatan atau perubahan yang mengalami penurunan.
Jika datang ke Bali, kawasan Pantai merupakan daerah tujuan wisata yang paling umum dan banyak dikunjungi oleh wisatawan baik domestik maupun mancanegara dari segala usia baik. Bali merupakan pulau kecil yang dikelilingi oleh laut, maka tidak heran jika Bali memiliki banyak sekali daerah tujuan wisata berupa kawasan pantai, salah satu dari sekian banyak pantai yang ada di Bali yaitu Pantai Dreamland. Pantai Dreamland terletak di Bali bagian Selatan tepatnya di kawasan Pecatu, Pantai Dreamland juga banyak dikunjungi wisatawan domestik maupun mancanegara. Seiring berjalananya waktu dan perkembangan pariwisata yang juga semakin pesat dan juga semakin banyaknya daerah tujuan wisata baru yang bermunculan yang bisa jadi menjadi lebih menarik dibanding dengan Pantai Dreamland. Sehingga dalam kondisi tersebut di Pantai Dreamland perlu diketahui mengenai kondisi eksisiting Pantai Dreamland serta pengembangan wisata di Pantai Dreamland.

\section{TINIAUAN PUSTAKA}

Penelitian ini menggunakan beberapa konsep sebagai landasan analisis dari data yang 
didapat, adapun beberapa konsep tersebut adalah :

\section{Konsep Pantai}

Pantai merupakan batas antara daratan dan lautan. Dalam Draft Pedoman Pengamanan dan Penanganan Pantai (Yuwono,2005), daerah pantai atau pesisir adalah suatu daratan beserta perairanya dimana pada daerah tersebut masih dipengaruhi baik oleh aktifitas darat maupun aktifitas laut. Pantai adalah daerah tepi perairan sebatas antara surut terendah dan pasang tertinggi.

2. Konsep Daerah Tujuan Wisata

Dalam Pengantar Pariwisata (Marpaung dan Bahar,2002) mengemukakan bahwa terdapat tiga elemen pariwisata, yaitu lokasi geografis yang mencakup daerah asal wisatawan, daerah tujuan dan daerah transit. Daerah tujuan wisata atau destinasi wisata adalah daerah yang memiliki obyek-obyek wisata yang menarik untuk dikunjungi oleh wisatawan lokal/domestik atau yang berasal dari berbagai negara (mancanegara) dan trsedianya fasilitas penunjang transportasi dan akomodasi. Di daerah tujuan wisatawan membutuhkan layanan jasa untuk menjawab tiga kebutuhan wisatawan, yaitu something to see, something to do dan something to buy.

3. Konsep Pengembangan Pariwisata

$$
\text { Menurut }
$$

(Suwantoro,

2002)

pengembangan yaitu memajukan dan memperbaiki atau meningkatkan sesuatu yang sudah ada. Dalam penelitian ini, pengembangan yang dimaksud adalah suatu upaya yang dilakukan untuk memajukan dan memperbaiki serta mengembangkan Pantai Dreamland agar terhindar dari stagnasi untuk masa kedepananya.

4. Teori siklus hidup destinasi

Menurut (Butler,1980) dalam The Canadian Geographer, pola yang dikemukakan di sini didasarkan pada konsep siklus produk, dimana penjualan produk pada awalnya perlahan-lahan lalu mengalami peningkatan, berjalan stabil, dan kemudian mengalami penurunan. Tahapan tersebut yaitu penemuan (exploration), keterlibatan (involvement), pengembagan (development), konsolidasi (consolidation), stagnasi (stagnation), Tahap Penurunan (Decline), Tahap Peremajaan (rejuvenation).

Tahapan yang dilalui daerah wisata diilustrasikan dalam gambar berikut :

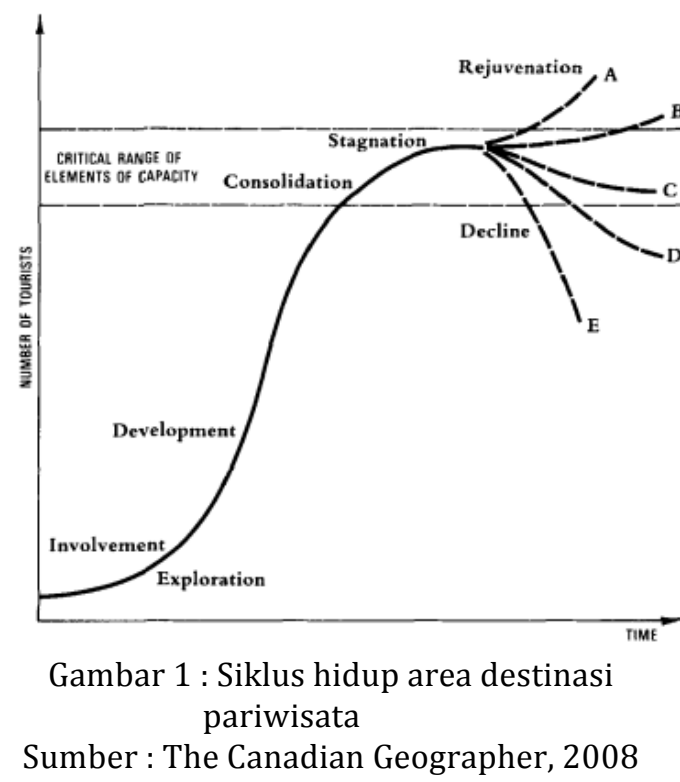

III. METODE

Penelitian ini dilakukan di Pantai Dreamlad yang berlokasi di kawasan Desa Pecatu, Kecamatan Kuta Selatan, Kabupaten Badung. Untuk mempermudah penulisan laporan ini agar lebih terarah dan berjalan baik, adapun ruang lingkup dalam penelitian ini yaitu

1. Kondisi eksisting Pantai Dreamland yang meliputi empat komponen utama produk wisata (4A) yaitu atraksi (attraction), kemudahan akses (accesibility), fasilitas (amenities), pelayanan tambahan (ancillary service), dan juga mengenai pekembangan Pantai Dreamland.

2. Pengembangan Pantai Dreamland yang ditinjau dengan teori Buttler dan di analisis menggunakan analisis SWOT untuk mendapatkan pengembangan yang sesuai untuk jangka waktu kedepan.

Jenis dan sumber data dalam penelitian ini menurut Bungin (2007:103). Jenis data kualitatif yang diperoleh pada penelitian ini berasal dari informan yang terkait dengan keberadaan Pantai Dreamland yaitu pengelolaan Pantai Dreamland, mengenai kondisi existing di Pantai Dreamland, data mengenai perkembangan pariwisata di Pantai Dreamland dengan menggunakan analisis tourism area life cycle. Sedangkan data kuantitatif yang diperoleh pada penelitian ini yaitu jumlah penduduk di Desa Pecatu dan luas wilayah Desa Pecatu. Sumber data primer dalam penelitian ini didapat secara langsung dri 
informan baik lisan maupun tulisan mengenai kondisi eksisting di Pantai Dreamland, sejarah Pantai Dreamland dan perkembangan Pantai Dreamland. Sedangkan data sekunder dalam penelitian ini mengenai sejarah Pantai Dreamland, kelembagaan pengelolaan Pantai Deamland, jumlah penduduk Desa Pecatu dan Luas wilayah Desa Pecatu.

Teknik pengumpulan data yang digunakan dalam penelitian ini yaitu : obesrvasi, wawancara, dan studi kepustakaan (Usman dan Akbar (2009:52). Teknik penentuan informan dalam penelitian ini yaitu menggunakan teknik prosedur purposif, untuk itu informan yang terpilih yaitu pihak pengelola Pantai Dreamland, wisatawan yang berkunjung ke Pantai Dreamland dan pedagang di Pantai Dreamland.

Teknik analisis data yang digunakan dalam penelitian ini menggunakan teknik analisis data kualitatif yaitu dengan mereduksi data, penyajian data dan penarikan kesimpulan atau verivikasi (Sugiyono, 2014). Dengan melakukan pengumpulan data mengenai kondisi existing Pantai Dreamland serta perkembangan Pantai Dreamland yang ditinjau dengan komponen produk wisata yang kemudian disajikan dalam bentuk uraian deskriptif. Untuk mengetahui pengembangan Pantai Dreamland yang baik dalam waktu mendatang, maka dilakukan juga dengan analisis dengan menggunakan SWOT. Penggunaan pendekatan SWOT disini untuk mengetahui keadaan dan apa saja yang harus ditingkatkan dan diminimalkan pada Pantai Dreamland agar pengembangan kedepannya menjadi lebih baik. hal tersebut meliputi :

1. Kekuatan (Strength) adalah faktor internal yang berupa keunggulan/kekuatan Pantai Dreamland yang menjadi pendorong atau pendukung pengembangan lebih baik kedepanya

2. Kelemahan (Weakness) adalah faktor internal yang dapat menghambat proses pengembangan Pantai Dreamland

3. Peluang (Oppotunities) adalah faktor eksternal atau kondisi yang mendatangkan keuntungan apabila dimanfaatkan secara efektif dan positif

4. Ancaman (Threats) adalah faktor eksternal yang dapat mendatangkan kerugian bagi pengembangan Pantai Dreamland.

Matrik ini menghasilkan 4 set kemungkinan alternatif strategis, yaitu :

1. Strategi SO : Strategi ini dibuat berdasarkan dengan memanfaatkan seluruh kekuatan untuk merebut dan memanfaatkan seluruh peluang sebesarbesarnya

2. Strategi ST : Merupakan strategi yang dibuat berdasarkan menggunakan kekuatan yang dimiliki untuk mengatasi ancaman

3. Strategi WO : Merupakan strategi yang diterapkan berdasarkan pemanfaatan peluang yang ada dengan cara meminimalkan kelemahan yang ada

4. Strategi WT : Strategi ini berdasarkan pada usaha untuk meminimalkan kelemahan yang ada serta menghindarkan ancaman.

Hasil persilangan dari matriks SWOT seperti terdapat pada tabel 1 :

Tabel 1 Matriks persilangan SWOT

\begin{tabular}{|c|c|c|}
\hline $\begin{array}{l}\begin{array}{r}\text { IFAS } \\
\text { (Internal } \\
\text { Factor } \\
\text { Analysis } \\
\text { Strategic) }\end{array} \\
\text { EFAS } \\
\text { (External) } \\
\text { Factor } \\
\text { Analysis } \\
\text { Strategic) }\end{array}$ & $\begin{array}{l}\text { Strenghts }(\mathrm{S}) \\
\text { tentukan 5-10 } \\
\text { faktor-faktor } \\
\text { kekuatan } \\
\text { internal }\end{array}$ & $\begin{array}{l}\text { Weaknes (W) } \\
\text { tentukan 5-10 } \\
\text { faktor-faktor } \\
\text { kelemahan } \\
\text { internal }\end{array}$ \\
\hline $\begin{array}{l}\text { Opportunities } \\
\text { (0) tentukan } \\
5-10 \text { faktor } \\
\text { peluang } \\
\text { eksternal }\end{array}$ & $\begin{array}{l}\text { Strategi SO } \\
\text { Ciptakan } \\
\text { strategi yang } \\
\text { menggunakan } \\
\text { kekuatan } \\
\text { untuk } \\
\text { memanfaatkan } \\
\text { peluang }\end{array}$ & $\begin{array}{l}\text { Strategi WO } \\
\text { Ciptakan } \\
\text { strategi yang } \\
\text { meminimalkan } \\
\text { kelemahan } \\
\text { untuk } \\
\text { memanfaatkan } \\
\text { peluang }\end{array}$ \\
\hline
\end{tabular}




\begin{tabular}{|l|l|l|}
\hline $\begin{array}{l}\text { Threats (T) } \\
\text { tentukan 5- }\end{array}$ & Strategi ST & Strategi WT \\
$\begin{array}{l}\text { 10 faktor } \\
\text { ancaman } \\
\text { eksternal }\end{array}$ & $\begin{array}{l}\text { Ciptakan } \\
\text { strategi yang } \\
\text { menggunakan } \\
\text { kekuatanuntuk } \\
\text { mengatasi } \\
\text { ancaman }\end{array}$ & $\begin{array}{l}\text { Ciptakan } \\
\text { strategi yang } \\
\text { meminimalkan } \\
\text { kelemahan } \\
\text { dan } \\
\text { mengkhindari } \\
\text { ancaman }\end{array}$ \\
& & \\
&
\end{tabular}

Sumber : Freddy Rangkuti (2002)

\section{HASIL DAN PEMBAHASAN}

Daya tarik wisata Pantai Dreamland terletak di Desa Pecatu, Kecamatan Kuta Selatan, Kabupaten Badung. Luas Desa Pecatu yaitu 26,41 $\mathrm{km}^{2}$. Pantai Dreamland berada dalam kawasan PT. Bali Pecatu Graha (BPG), PT. Bali Pecatu Graha (BPG) yang sempat heboh pada tahun 1996 karena ingin mendirikan resort super mewah dengan nama "Pecatu Indah Resort".

Belum diketahui secara pasti bagaimana asal-usul dari Pantai Dreamland tersebut, namun jika ditinjau menurut arti secara harafiah kata dreamland berarti "tanah impian". Menurut cerita hal tersebut berawal dari sebuah proyek perumahan dan objek wisata yang terbengkalai karena suatu hal. Sementara di sisi lain masyarakat di daerah tersebut begitu berharap banyak pada proyek tersebut agar segera diteruskan, agar kehidupan masyarakat yang tadinya hanya sebagai petani bisa terangkat jika daerahnya dialihfungsikan menjadi daerah pariwisata. Mungkin karena begitu besarnya harapan dari penduduk untuk menjadikan lahan atau tanah yang menjadi tempat kelahiran tersebut menjadi sumber penghidupan yang layak dari sektor pariwisata, maka disebutlah lokasi tersebut menjadi "Dreamland" yang berarti "tanah impian".

Namun terlepas dari cerita diatas, dilain cerita asal kata dreamland tersebut berasal dari penamaan oleh wisatawan yang pertama kali mengunjungi Pantai Dreamland. Karena dahulu sebelum Pantai Dreamland ramai dikunjungi wisatawan, akses untuk menuju Pantai Dreamland masih sangat sulit untuk dilewati, dimana harus melewati bukit kapur yang terjal dan keadaan jalan yang naik turun. Karena sulitnya medan untuk menuju Pantai Dreamland tersebut maka memerlukan sebuah perjuangan yang tidak mudah. Setelah menempuh perjalanan yang melelahkan, lalu menemukan Pantai Dreamland dengan pasir putih dan tebing mejulang yang sangat indah, bersih dari sampah, ombak yang bergulunggulung serta air yang jernih dan keadaan pantai yang masih sepi, hal tersebut membuat wisatawan yang pertama datang menjadi lebih relax. Sehingga tempat tersebut dinamakan dengan "Dreamland" dimana tempat yang tenang dan bersih merupakan tempat yang diinginkan oleh semua orang.

Walaupun terdapat dua versi cerita mengenai asal-usul nama Pantai Dreamland, namun keduanya memiliki kesamaan inti cerita yaitu dimana Pantai Dreamland merupakan suatu tanah yang diinginkan atau suatu tempat yang menjadi sebuah impian.

\section{Komponen Produk Wisata Pada Pantai Dreamland}

Kondisi eksisting Pantai Dreamland jika ditinjau dari adanya komponen produk wisata yang terdiri dari :

\section{Attraction}

Atraksi merupakan sesuatu yang unik dan merupakan suatu ciri khas yang dimiliki suatu daerah yang dapat membedakan daerah tersebut dengan daerah yang lain. Atraksi wisata yang terdapat di Pantai Dreamland yaitu :

a. Ombak yang besar

Pantai Dreamland memiliki gulungan ombak yang dahsyat dan tidak ada hentinya, sehingga cocok untuk wisatawan yang memiliki hobi surfing. Banyak pula tempat penyewaan papan surfing di sekitar pinggir pantai. Selain surfing banyak juga wisatawan yang berenang atau sekedar bermain air menikmati sensasi ombak di Pantai Dreamland.

b. Pemandangan Pantai Dreamland.

Pemandangan di Pantai Dreamland sangat menarik untuk dinikmati, terutama ketika sunset. Pantai berpasir putih dengan tebing yang menjulang tinggi disekeliling pantai, suasana pantai yang tidak begitu ramai dipenuhi oleh wisatawan akan membuat terasa 
nyaman dan serasa berada pada sebuah private beach.

c. Memancing

Selain melakukan surfing, berenang ataupun sekedar bermain air, terdapat juga pengunjung yang sedang memancing. Kebanyakan pengunjung yang memancing datang pada saat sore hari, sehingga memancing sambil menikmati keindahan panorama sunset di Pantai Dreamland.

d. Pantai yang bersih

Kawasan pantai Dreamland merupakan pantai dengan pasir putih yang bersih, tidak ada sampah yang berserakan di sekitar pantai dan air laut di Pantai Dreamland juga terlihat jernih berwarna biru dan bersih serta tidak terlihat sampah yang mengapung terbawa oleh ombak.

\section{Amenities}

Amenities merupakan segala sarana dan prasarana yang diperlukan oleh wisatawan guna mendukung segala aktifitas yang dilakukan selama berada di daerah tujuan wisata. Sarana dan Prasarana yang terdapat di Pantai Dreamland yaitu :

a. Tempat parkir

Tempat parkir di Pantai Dreamland terdapat 2 tempat, untuk kendaraan roda dua dan roda empat parkir di area sebelum pintu masuk menuju Pantai Dreamland. Sedangkan untuk bus, tempat parkir nya berada di central park yang tidak jauh dari Pantai Dreamland. Biaya parkir untuk roda dua sebesar Rp,5.000, untuk roda empat sebesar $\mathrm{Rp}, 10.000$, dan untuk bus sebesar Rp,15.000,

b. Restoran

Pada kawasan Pantai Dreamland terdapat 1 restoran dan juga 2 warung makan. Restoran tersebut terdapat di bibir pantai sehingga Pantai Dreamland menjadi sebuah view yang menarik ketika sedang menyantap makanan di restoran tersebut.
Selain restoran, terdapat juga 2 buah warung makanan yang berada diantara deretan kios souvenir. Selain itu terdapat juga 4 pedagang makanan disekitar area tempat parkir Pantai Dreamland.

c. Money changer

Pada kawasan Pantai Dreamland diantara deretan kios-kios souvenir juga terdapat sebuah fasilitas money changer yang dapat digunakan oleh wisatawan untuk menukarkan uang rupiah.

d. Toilet

Pada Pantai Dreamland memiliki 2 buah toilet yang dapat digunakan oleh wisatawan, toilet tersebut terletak di bawah dekat pantai dan diatas diantara kios souvenir.

e. Kios souvenir

Setelah masuk kawasan Pantai Dreamland, maka akan ditemukan beberapa penjual souvenir yang terlihat bersusun rapi disebelah kanan sepanjang jalan menuju pantai. Terdapat sekitar 24 kios souvenir di sepanjang jalan tersebut. Kios-kios tersebut banyak menjual pakaian pantai, kain pantai, kaos bali, baju rajut, acecoris berupa kalung dan gelang, dll.

f. Minimart

Pada kawasan Pantai Dreamland diantara deretan kios-kios souvenir juga terdapat sebuah minimart bernama "Dreamland mart" yang didalamnya menjual kebutuhan wisatawan. Di sebelah minimart tersebut juga terdapat sebuah fasilitas meja beserta tempat duduk, yang dapat digunakan oleh wisatawan untuk sekedar duduk sambil menikmati suasana pantai Dreamland.

g. Tempat penyewaan papan surfing Pada sekitar bibir Pantai Dreamland terdapat beberapa tempat yang menyewakan papan surfing. Terdapat sekitar 9 tempat penyewaan papan surfing disekitar pantai tersebut. Selain penyewaan papan surfing pada tempat tersebut 
juga memberikan pelayanan untuk belajar surfing secara singkat.

h. Payung pantai dan tempat duduk Untuk wisatawan yang ingin menikmati keindahan pantai Dreamland tetapi tidak ingin kepanasan, wisatawan dapat menyewa sebuah payung pantai beserta tempat duduk yang ada di sekitar bibir pantai. Terdapat juga beberapa ibu-ibu disekitar pantai yang bekerja untuk memberikan service kepada wisatawan berupa massage.

\section{Accesbility}

Aksesbilitas (accesbility) yaitu merupakan suatu kemudahan untuk mengakses atau merupakan sebuah pintu masuk utama untuk menuju daerah tujuan wisata guna mendukung kegiatan kepariwisataan. Karena jalan utama untuk masuk area Pantai Dreamland merupakan gate dari pecatu indah resort maka jalan tersebut sudah tergolong sangat baik, dan bagus serta mudah sekali untuk ditemukan. Segala jenis transportasi kendaraan dapat digunakan, baik roda dua, roda empat maupun bus dapat melewati jalan tersebut.

Tetapi setelah memasuki gate dari pecatu indah resort penunjuk arah untuk menuju Pantai Dreamland masih kurang, dan karena letak pantai nya yang masuk tidak terlihat dari jalan sehingga terkadang hal tersebut membuat wisatawan yang baru pertama kali berkunjung menjadi bingung.

\section{Ancilary service}

Pantai Dreamland mulai banyak dikunjungi wisatawan setelah dibukanya kawasan wisata Bali Pecatu Graha. Fasilitas jalan untuk menuju ke Pantai Dreamland serta fasilitas parkir adalah milik dari PT. Bali Pecatu Graha sebagai pengelola kawasan. Hingga saat ini pihak desa adat Pecatu masih belum membentuk badan pengelola untuk Pantai Dreamland, pengelolaan hanya sebatas mendirikan kios yang lalu disewakan kepada para pedagang dan untuk tiap tahun nya pedagang yang menempati kios tersebut harus membayar biaya penyewaan sebesar 10 juta. Pengelolaan secara utuh di Pantai Dreamland oleh desa adat Pecatu masih dalam tahap perencanaan.

\section{Perkembangan Pantai Dreamland}

Tahap perkembangan dalam penelitian ini ditinjau dari kondisi eksisting komponen produk wisata di Pantai Dreamland. Dengan adanya perkembangan wisata di Pantai Dreamland, hal tersebut membuat karakteristik fisik dan sosial dari kawasan Pantai Dreamland sedikit berubah. Pantai Dreamland telah mengalami siklus yang terdiri dari tahap eksplorasi dan tahap keterlibatan. Tahapan dari perkembangan wisata di Pantai Dreamland yaitu sebagai berikut :

1. Tahap eksplorasi

Belum diketahui secara pasti kapan pertama kali Pantai Dreamland mulai dikunjungi oleh wisatawan. Namun menurut hasil wawancara dengan salah satu narasumber, dulu pada tahun 1988 tempat tersebut sudah dikunjungi oleh wisatawan dan namanya pun sudah disebut dengan Pantai Dreamland. Pada tahap eksplorasi aksesbilitas masih sangat kurang, atraksi wisata hanya ombak yang alami untuk atraksi buatan juga belum ada, belum adanya sarana dan prasarana penunjang kegiatan wisata serta belum ada pengelolaan Pantai Dreamland.

Pada tahun 1988 untuk menuju lokasi Pantai Dreamland sulit untuk dicapai karena akses menuju pantai tersebut masih sangat sulit untuk dilalui. Oleh karena itu hanya wisatawan tertentu yang memiliki jiwa petualang yang berminat untuk datang ke Pantai Dreamland. Pada saat itu keadaan di Pantai Dreamland masih terlihat sangat alami, bagus dan juga masih sangat sepi, belum ada banyak wisatawan yang datang.

Pada tahun 1996 mulai berdiri proyek dari PT. Bali Pecatu Graha (BPG) yang akan membangun resort mewah di sekitar area tersebut. Karena letak Pantai Dreamland yang berada didalam area tanah milik dari PT. Bali Pecatu Graha sehingga sudah mulai terjadi pembenahan kawasan dan akses jalan 
yang dulunya terjal berbatu kapur sehingga berubah menjadi jalan beraspal yang bagus, sehingga mudah untuk dilewati. Namun pada tahun 1998 proyek yang baru selesai $25 \%$ tersebut sempat berhenti karena terjadi krisis moneter di negara Indonesia.

\section{Tahap Keterlibatan}

Pada tahun 2010 karena akses menuju Pantai Dreamland yang sudah mudah, sehingga mulai banyak wisatawan yang mengunjungi Pantai Dreamland. Pembangunan proyek PT. Bali Pecatu Graha sudah berjalan, mulai banyak gedung-gedung mewah berdiri dengan kokoh didalam area tersebut. Bangunanbangunan hotel bermunculan, salah satunya yaitu Dreamland World Hotel yang berada tepat disebelah Pantai Dreamland. Dengan adanya hotel tersebut, sehingga pedagang-pedagang yang dulunya berjualan dengan membawa dagangannya menuju ke sekitar kawasan pantai, hal tersebut menjadi dilarang karena dianggap mengotori kawasan pantai dan merusak pemandangan di Pantai.

Sehingga pada tahun 2011 pemerintah desa adat Pecatu mulai melakukan pembangunan kios-kios dengan ukuran $4 \times 1$ meter yang lalu disewakan untuk para pedagang agar berpindah menuju kios yang telah disediakan, selain itu juga membangun toilet serta kamar mandi. Dengan begitu hanya terdapat payung pantai yang berjejer rapi di bibir pantai.

Hal tersebut berlangsung hingga saat ini dan terlihat terjadi peningkatan terhadap banyaknya wisatawan yang mengunjungi Pantai Dreamland. Terdapat pengunjung domestik yang sedang kunjungan studi, pengunjung lokal yang hanya sekedar jalan-jalan untuk melepas penat dan banyak juga wisatawan mancanegara yang datang ke Pantai Dreamland. Pantai Dreamland mulai ramai dikunjungi pada saat siang hari pukul 11.00 wita hingga sore hari pukul 18.00 wita.

\section{Pengembangan Pantai Dreamland}

Pengembangan di Pantai Dreamland masih belum dilakukan secara utuh oleh pengelola yaitu dari Desa Adat Pecatu hanya dalam tahap pembuatan fasilitas-fasilitas serta kios-kios untuk pedagang. Sehingga, menurut teori siklus hidup area destinasi (tourism area lif cycle) Pantai Dreamland pada saat ini masih dalam tahap keterlibatan (involvement). Seperti dalam tahapan dari siklus hidup area destinasi tahapan yang selanjutnya yang akan dialami oleh Pantai Dreamland yaitu adalah tahap pengembangan (development).

Untuk menindak lanjut kedalam tahap pengembangan, maka diperlukan analisis dengan menggunakan kekuatan, kelemahan, peluang dan hambatan (SWOT) pada Pantai Dreamland. Analisis yang perlu dilakukan tersebut yaitu :

\section{Kekuatan (strength)}

a. Lokasi yang mudah dijangkau

Lokasi Pantai Dreamland yang dekat dengan jalan utama dan tidak terlalu jauh dari bandara sehingga mudah untuk dijangkau.

b. Kondisi jalan yang baik

Dengan kondisi jalan menuju Pantai Dreamland yang sudah di aspal serta kondisi jalan yang lebar dan bagus beserta trotoar di samping kanan dan kiri jalan, yang dapat digunakan oleh pejalan kaki maupun untuk jogging trek. Keadaan tersebut sangat mendukung kenyamanan pada perjalanan wisatawan yang ingin menuju Pantai Dreamland.

c. Kebersihan pantai yang terjaga

Pantai Dreamland merupakan pantai yang bersih tidak terlihat sampah disekitar kawasan pantai. Tidak hanya di area pantai namun air laut di Pantai Dreamland juga bersih tidak terlihat sampah yang menggenang dan terbawa oleh ombak.

d. Ombak pantai yang besar

Pantai Dreamland memiliki ombak yang besar dan stabil, sehingga sangat cocok digunakan untuk olahraga surfing.

2. Kelemahan (weakness)

a. Tidak ada fasilitas Tourist Information Center (TIC)

Dengan tidak adanya fasilitas Tourist Information Center (TIC) dan loket untuk tiket masuk, sehingga ketika ingin masuk Pantai Dreamland hanya membayar untuk biaya parkir kendaraan.

b. Sumber daya manusia (SDM) 
Jumlah penduduk di Desa Pecatu yaitu berjumlah 7.257 jiwa yang terdiri dari 3.704 jiwa penduduk laki-laki dan 3.553 jiwa penduduk perempuan dengan sekitar $48 \%$ adalah berusia produktif. Namun kebanyakan dari mereka memiliki tingkat pendidikan akhir yang rendah yaitu hanya tamat SD, sehingga hanya bekerja sebagai penyedia jasa, pemilik kios souvenir, pelayan restaurant dll, dan juga tidak banyak terlihat pemuda yang bekerja di area Pantai Dreamland.

c. Promosi daerah tujuan wisata yang kurang Kegiatan promosi pada Pantai Dreamland masih belum dilakukan secara gencar dikarenakan Pantai Dreamland masih belum dikelola dengan baik.

\section{Peluang (opportunities)}

a. Pemandangan pantai yang indah

Pemandangan Pantai Dreamland yang indah dan kondisi pantai yang masih sepi sehingga membuat wisatawan yang datang menjadi lebih nyaman dengan kondisi tersebut.

b. Akan dibuatnya akses jalur baru

Untuk lebih mempermudah akses ketika menuju Pantai Dreamland akan dibuatkan sebuah jalur baru agar tidak masuk melewati jalur Pecatu Indah Resort.

\section{Ancaman (threats)}

a. Persaingan dengan daerah tujuan wisata lain

Selain Pantai Dreamland, masih banyak lagi daerah tujuan wisata yang sedang berkembang di Kabupaten Badung misalnya pada kawasan sekitar Nusa Dua, Jimbaran dan Kuta. Dimana hal tersebut dapat mengakibatkan terjadinya persaingan antar daerah tujuan wisata guna menarik wisatawan untuk datang. Persaingan antar daya tarik wisata diharapkan dapat meningkatkan kreativitas yang dapat mendongkrak potensi yang ada di daerah tujuan wisata.

b. Area pantai yang berada di dalam kawasan sebuah resort

Pantai Dreamland berada didalam kawasan sebuah resort, sehingga untuk menuju Pantai Dreamland harus melewati sebuah pintu masuk dari resort tersebut. Maka ketika masuk kawasan resort tersebut harus melewati pos pengamanan dan akan diperiksa oleh pihak pengamanan resort. Disisi lain hal tersebut merupakan sebuah prosedur keamanan namun hal tersebut juga membuat wisatawan merasa enggan untuk diperiksa. Karena letak yang berada dalam kawasan resort, hal tersebut juga dapat membuat Pantai Dreamland dapat di claim oleh pemilik resort agar dapat digunakan menjadi private beach, sehingga tidak ada wisatawan lain selain yang tinggal di area resort tersebut.

Berikut merupakan strategi yang dapat digunakan untuk pengembangan Pantai Dreamland, yaitu :

1. Strategi SO : Dengan lokasi Pantai Dreamland yang strategis serta kebersihan pantai dan ombak yang besar, dengan hal tersebut Pantai Dreamland lebih diminati oleh wisatawan. Sehingga akan dibuatnya akses jalur baru tersebut dapat segera dilakukan.

2. Strategi ST : Memberikan kemudahan akses menuju lokasi Pantai Dreamland untuk mengatasi persaingan dengan Daerah Tujuan Wisata yang lain

3. Strategi WO : Membuatkan fasilitas Tourist Information Center (TIC) dan loket untuk tiket masuk. Serta membuka akses baru dan menambah upaya promosi untuk mendatangkan wisatawan

4. Strategi WT : Melakukan promosi dengan gencar untuk meminimalkan persaingan dengan pantai lain, serta lebih menarik wisatawan agar mengunjungi Pantai Dreamland

Bedasarkan data tersebut Pantai Dreamland dapat dikembangkan menjadi sebuah daya tarik wisata yang indah dan banyak dikunjungi wisatawan. Untuk mendukung hal tersebut dilakukan dengan dibukanya akses baru untuk menuju Pantai Dreamland agar tidak perlu masuk melalui resort tersebut. Dengan kemudahan aksesbilitas tersebut merupakan nilai tambah dari Pantai Dreamland, sehingga persaingan dengan daya tarik wisata yang lain dapat teratasi. Dengan dibuatnya fasilitas Tourist Information Center (TIC) dan loket tiket masuk, maka akan memudahkan wisatawan untuk memperoleh informasi mengenai daya tarik wisata Pantai Dreamland. Serta melakukan 
promosi oleh dinas pariwisata daerah maupun pengelola dari pihak desa adat, hal tersebut dilakukan agar banyak orang mengetahui Pantai Dreamland serta banyak wisatawan mengunjungi Pantai Dreamland.

\section{SIMPULAN DAN SARAN}

Kondisi eksisting Pantai Dreamland terhitung sudah baik, jika ditinjau dari adanya komponen produk wisata yaitu : Atraksi (atraction) yang terdiri dari ombak yang besar, pemandangan yang indah, memancing dan pantai yang bersih, atraksi alam di Pantai Dreamland hanya standart seperti pada pantai yang lain, namun kondisi pantai yang masih sepi tersebut menarik wisatawan untuk datang. Sarana dan pasarana (amenities) yang terdiri dari tempat parkir, restoran, money changer, toilet, kios souvenir, minimart, penyewaan papan surfing, payung pantai tempat duduk, sarana dan prasarana di Pantai Dreamland masih kurang karena tidak adanya Tourist Information Center (TIC). Aksesbilitas (accesbility) karena jalan utama untuk menuju area Pantai Dreamland merupakan gate dari pecatu indah resort maka jalan tersebut sudah sangat baik, bagus, tentunya tidak berlubang serta mudah sekali untuk ditemukan. Segala jenis transportasi kendaraan pun dapat digunakan, baik roda dua, roda empat maupun bus dapat melewati jalan tersebut. Pelayanan tambahan (ancillary service) fasilitas jalan untuk menuju ke Pantai Dreamland serta fasilitas parkir adalah milik dari PT. Bali Pecatu Graha sebagai pengelola kawasan. Pihak desa adat Pecatu masih belum membentuk badan pengelola untuk Pantai Dreamland, pengelolaan hanya sebatas mendirikan kios yang lalu disewakan kepada para pedagang

Perkembangan Pantai Dreamland jika dilihat indikator-indikator tersebut yang lalu ditinjau dengan menggunakan tourism area life cycle sedang berada dalam tahap keterlibatan (involvment). Analisis menggunakan kekuatan, kelemahan, peluang dan ancaman SWOT menghasilkan strategi yang dapat digunakan untuk pengembangan Pantai Dreamland. Strategi tersebut yaitu menjaga kebersihan pantai serta membuka akses baru untuk menarik wisatawan, memberikan kemudahan akses menuju lokasi Pantai Dreamland untuk mengatasi persaingan dengan Daerah Tujuan Wisata yang lain, membuka akses baru dan menambah upaya promosi untuk mendatangkan wisatawan dan melakukan promosi dengan gencar untuk lebih menarik wisatawan agar mengunjungi Pantai Dreamland.

\section{DAFTAR PUSTAKA}

Yuwono, N., 2005. Draft Pedoman Pengamanan dan Penanganan Pantai. Departmen Pekerjaan Umum, Jakarta

Marpaung, Happy dan Bahar, Herman. 2002. Pengantar Pariwisata. Bandung: Alfabeta

Suwantoro, G. 2002. Dasar-Dasar Pariwisata. Yogyakarta : Andi

Bungin, Burhan. 2007. Penelitian Kualitatif. Jakarta: Prenanda Media Grup

Butler, Richard W. .2008. The Concept of A Tourist Area Cycle of Evolution: Implications for Management of Resources. Canadian Geographer

Sugiyono. 2014. Metode Penelitian Kuantitatif Kualitatif dan $R \& D$. Bandung : Alfabeta

Usman, Husaini dan Akbar, Purnomo Setiady. 2009. Metodolgi Penelitian Sosial. Jakarta: Bumi Aksara

Rangkuti, Feddy. 2002. Analisis SWOT Teknik Membedah Kamus Bisnis. Jakarta : Gramedia Pustaka Utama 